\title{
Photodynamic Therapy for Oral Candidosis: a new option?
}

\author{
Cinzia Casu ${ }^{1 *}$, Matteo Fanuli ${ }^{2}$ and Luca Viganò ${ }^{3}$ \\ ${ }^{1} D D S$, Private Dental Practice, Italy \\ ${ }^{2} R D H$, Department of Biomedical, Surgical and Dental Sciences, University of Milan, Italy \\ ${ }^{3}$ DDS, Department of Radiology, University of Milan, Italy
}

Submission: March 23, 2018; Published: May 11, 2018

*Corresponding author: Cinzia Casu, DDS, Private Dental Practice, Cagliari, Italy, Email: ginzia.85@hotmail.it

Abstract

Candida Albicans is a ubiquitous polymorphic fungus that is part of the normal microbiota of healthy individuals. This infection occurs in patients that have some risk factor such as the use of dentures, corticosteroid inhalers, cigarettes, broad-spectrum antibiotics, and immunosuppressive and chemotherapeutic agents. Photodynamic Therapy (PDT) relies on the interaction between a photosensitizer, a light with the appropriate wavelength, and the presence of oxygen. Studies published in scientific literature on the use of PDT in oral candidiasis are mainly in vitro studies; very few are in vivo and clinical studies. We can say that the results in the literature show that PDT works, but we do not have a replicable protocol. Patient studies should have larger samples and with longer follow-up.

\section{Introduction}

Candida Albicans is a ubiquitous polymorphic fungus that is part of the normal microbiota of the gastrointestinal and reproductive tracts of healthy individuals. In order to colonize the oral mucosa C. albicans must adhere to the epithelial cell lining while avoiding being killed by host antimicrobial factors. This infection occurs in a diverse group of patients that have some risk factor such as the use of dentures, corticosteroid inhalers, cigarettes, broad-spectrum antibiotics, and immunosuppressive and chemotherapeutic agents. Patients with HIV, diabetes, and iatrogenic or autoimmune-induced dry mouth are also at substantial risk for Oral Candidosis [1].

Photodynamic Therapy (PDT) relies on the interaction between a photosensitizer, a light with the appropriate wavelength, and the presence of oxygen. The reaction between the 3 elements generates ROS in cells that take up the photosensitizer, causing cell death by necrosis or apoptosis, but spares the surrounding tissue [2]. PDT was used in literature for the treatment of oral disease, such as oral lichen planus [3], oral pre-cancerous lesions [4] and periodontal infections [5].

Studies published in scientific literature on the use of photodynamic therapy in oral candidiasis are mainly in vitro studies. In a recent work the authors aimed to determine the efficacy of a PDT method based on light curing units' blue LEDs combined to a plaque-disclosing composition (5\% erythrosine) against $\mathrm{C}$. albicans in culture and in a murine model of oral candidosis [6]. The authors found that PDT completely inactivated C. albicans planktonic cells and biofilm [6]. Azizi et al. [7] found, in an in vitro study, that a combination of Indocyanine Green and laser light of $808 \mathrm{~nm}$ was better than other light's wavelength and Methylen Blue to kill oral Candidosis [7]. Pereira Costa et al. [8] Showed in their work that C. albicans and C. dubliniensis were susceptible to erythrosine- and LED-mediated PDT, but the biofilms of both Candida species were more resistant than their planktonic counterparts [8]. Hosseini et al. [9] found that the photodynamic therapy effect on standard suspension of Candida species using 4 different sensitizer: methylene blue, aniline blue, malachite green and crystal violet, is the same, with great decrease in CFU [9]. Pupo et al. [10] in their in vitro work concluded that the number of viable $\mathrm{C}$. albicans cells was reduced significantly after PDT using Methylen Blue or mainly Toluidine Blue associated to diode laser irradiation. Their data proved the efficacy of PDT against C. albicans cells, regardless of the photosensitizer used [10].

There are works in the literature on animal models. Carmello et al. [11] used Photodithazine (PDZ) as photosensitizer and the results of their study was that it was effective as Nystatin in the inactivation of C. albicans [11]. Another study underline the effectiveness of Methylen Blue [12], meanwhile Kadhemi et al. [13] reported that in mice model there are no difference between concentrations and type of photosensitizer, but confirmed the effectiveness of PDT [13]. 
Curcumin-mediate and rose bengal- and eosin Y-mediated PDT is proposed for treatment of oral candidosis [14,15] and other in vitro and animal studies demonstrate that PDT was effective also with different types of illumination $[16,17]$. Very few clinical studies are written in scientific literature. The most important is that of Mima et al. [18] They compared the use of Nystatin and haematoporphyrin derivative (Photogem)- mediate PDT for treatment of patients with dentures stomatitis. Authors concluded that both treatments significantly reduced the CFU/ $\mathrm{mL}$ at the end of the treatments and on day 30 of the follow-up period [18].

Recently a preliminary study reports five clinical cases of patients with denture stomatitis (DS) treated with PDZmediated a PDT [19]. They were submitted to PDT 3 times a week for 15 days. In each session PDZ gel was applied on the upper prostheses and on the palate of the patients for 20 minutes, then, illuminated by a light emitting diode at $660 \mathrm{~nm}$. Three patients completely healed after a PDT treatment. One individual demonstrated reduction in palatal inflammation and another was refractory. The $\mathrm{CFU} / \mathrm{mL}$ values obtained in the last microbiological collection were lower than those found before the treatment in all cases [19].

\section{Conclusion}

In conclusion we can say that the results in the literature show that PDT works, but we do not have a replicable protocol. Patient studies should have larger samples and with longer follow-up. I think PDT obtained an increased interest by clinicians and deserve severe clinical trials. I believe that scientific literature should be more oriented in the search for a repeatable protocol for the treatment of a very frequent pathology such as oral candidosis.

\section{References}

1. Swidergall M, Filler SG (2017) Oropharyngeal Candidiasis: Fungal Invasion and Epithelial Cell Responses. PLoS Pathog 13(1): e1006056.

2. Rkein AM, Ozog DM (2014) Photodynamic Therapy. Dermatol Clin 32(3): 415-425.

3. Barbosa FI, Araújo PV, Machado LJC, Magalhães CS, Guimarães MMM, et al. (2018) Effect of photodynamic therapy as an adjuvant to nonsurgical periodontal therapy: periodontal and metabolic evaluation in patients with type 2 diabetes mellitus. Photodiagnosis Photodyn Ther.

4. Gondivkar SM, Gadbail AR, Choudhary MG, Vedpathak PR, Likhitkar MS (2018) Photodynamic treatment outcomes of potentially-malignant lesions and malignancies of the head and neck region: A systematic review. J Investig Clin Dent 9(1).

5. Mirza S, Rehman N, Alrahlah A, Alamri WR, Vohra F (2018) Efficacy of photodynamic therapy or low level laser therapy against steroid therapy in the treatment of erosive-atrophic oral lichen planus. Photodiagnosis Photodyn Ther 21: 404-408.

6. da Silva NR, Ribeiro DG, Issa JPM, Bonfá K, Menezes MS, et al. (2017) Preclinical study of a cost-effective photodynamic therapy protocol for treating oral candidoses. Lasers Med Sci 32(6):1253-1260.

7. Azizi A, Amirzadeh Z, Rezai M, Lawaf S, Rahimi A (2016) Effect of photodynamic therapy with two photosensitizers on Candida albicans. J Photochem Photobiol B 158: 267-273.

8. Costa AC, de Campos Rasteiro VM, Pereira CA, da Silva Hashimoto ES, Beltrame M (2011) Susceptibility of Candida albicans and Candida dubliniensis to erythrosine- and LED-mediated photodynamic therapy. Arch Oral Biol 56(11): 1299-1305.

9. Hosseini N, Yazdanpanah S, Saki M, Rezazadeh F, Ghapanchi J, et al. (2016) Susceptibility of Candida albicans and Candida dubliniensis to Photodynamic Therapy Using Four Dyes as the Photosensitizer. J Dent (Shiraz) 17(4): 354-360.

10.10. Pupo YM, Gomes GM, Santos EB, Chaves L, Michel MD, et al. (2011) Susceptibility of Candida albicans to photodynamic therapy using methylene blue and toluidine blue as photosensitizing dyes. Acta Odontol Latinoam 24(2): 188-192.

11. Carmello JC, Alves F, G Basso F, de Souza Costa CA, Bagnato VS, et al. (2016) Treatment of Oral Candidiasis Using Photodithazine $®$ Mediated Photodynamic Therapy In vivo. PLoS One 11(6): e0156947.

12. Freire F, Ferraresi C, Jorge AO, Hamblin MR (2016) Photodynamic therapy of oral Candida infection in a mouse model. J Photochem Photobiol B 159: 161-168.

13. Khademi H, Torabinia N, Allameh M, Jebreilamtigh HR (2014) Comparative evaluation of photodynamic therapy induced by two different photosensitizers in rat experimental candidiasis. Dent Res J (Isfahan) 11(4): 452-459.

14. Dovigo LN, Carmello JC, de Souza Costa CA, Vergani CE, Brunetti IL, et al. (2013) Curcumin-mediated photodynamic inactivation of Candida albicans in a murine model of oral candidiasis. Med Mycol 51(3): 243251.

15. Freire F, Costa AC, Pereira CA, Beltrame Junior M, Junqueira JC, et al. (2014) Comparison of the effect of rose bengal- and eosin Y-mediated photodynamic inactivation on planktonic cells and biofilms of Candida albicans. Lasers Med Sci 29(3): 949-955.

16. Scwingel AR, Barcessat AR, Núñez SC, Ribeiro MS (2012) Antimicrobial photodynamic therapy in the treatment of oral candidiasis in HIVinfected patients. Photomed Laser Surg 30(8):429-432.

17. Fabio CA, Yolanda MB, Carmen GM, Francisco C, Antonio Julián B, et al. (2016) Use of photodynamic therapy and chitosan for inactivacion of Candida albicans in a murine model. J Oral Pathol Med 45(8): 627-633.

18. Mima EG, Vergani CE, Machado AL, Massucato EM, Colombo AL, et al. (2012) Comparison of Photodynamic Therapy versus conventional antifungal therapy for the treatment of denture stomatitis: a randomized clinical trial. Clin Microbiol Infect 18(10): E380-E388.

19. Alves F, Alonso GC, Carmello JC, Mima EGO, Bagnato VS, et al. (2017) Antimicrobial Photodynamic Therapy mediated by Photodithazine ${ }^{\circledR}$ in the treatment of denture stomatitis: a case report. Photodiagnosis Photodyn Ther 21: 168-171. 
This work is licensed under Creative Commons Attribution 4.0 License

DOI: 10.19080/JOJCS.2018.06.555698

\section{Your next submission with Juniper Publishers} will reach you the below assets

- Quality Editorial service

- Swift Peer Review

- Reprints availability

- E-prints Service

- Manuscript Podcast for convenient understanding

- Global attainment for your research

- Manuscript accessibility in different formats ( Pdf, E-pub, Full Text, Audio)

- Unceasing customer service

Track the below URL for one-step submission https://juniperpublishers.com/online-submission.php 